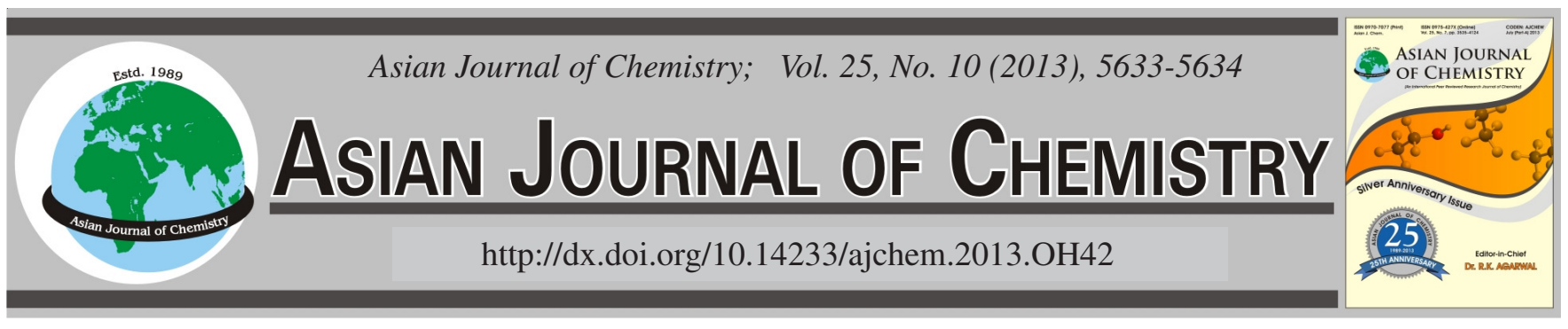

\title{
Wet Foams Stabilized to Self-Setting Porous Ceramics $\dagger$
}

\author{
Jung Gyu Park, Ashish Pokhrel, Bijay Basnet, Wei Zhao and Ik Jin Kim*
}

Department of Advanced Materials Science and Engineering, Institute of Processing and Application of Inorganic Materials, Hanseo University, Seosan city, Chungnam, Republic of Korea

*Corresponding author: E-mail: ijkim@ hanseo.ac.kr

This study presents a novel method to produce self-setting inorganic foams with unique setting time and pore structure. The combination of the particle-stabilized foams with Portland cement reaction leads to a macro porous ceramic material which can be shaped and consolidated at room temperature. The foam microstructure and porosity can be tailored varying different parameters like setting temperature, humidity, cement and setting accelerator concentration. The final microstructure featured a porosity of nearly $65 \%$ and a unique pore structure with prevailing hydration reaction of cement. As a result, self-setting ceramic composites with porosities ranging from 40 to $65 \%$ and pores with sizes between $100 \mu \mathrm{m}$ to $1 \mathrm{~mm}$ were achieved.

Key Words: Self-setting wet foams, Cement reaction, Porous ceramics, Porosity.

Key Words: Self-setting wet foams, Cemi reaction, Porous ceramics, Porosity.

\section{INTRODUCTION}

Porous ceramics with controlled microstructure and different compositions have increasing number of applications ${ }^{1,2}$. Most of the processing routes for the porous ceramics utilize the drying and sintering step to consolidate foams or emulsions and give the final microstructure and strength. To overcome the various steps of drying and sintering procedures a new process was proposed as described in the literature ${ }^{3,4}$. To go through this process, we applied recently developed direct foaming process for fabricating porous ceramics ${ }^{2}$ where particle stabilized foams are prepared by the process of in situ hydrophobization. The resulting foams generated are stable against bubble coarsening and drainage and the bubble size and porosity could be tailored in the wide range by the processing and compositional parameters. To in situ modify the wetting of the particle surface, short chain amphiphilic molecules are electrostatically adsorbed or by the ligand exchange reaction when stabilized through propyl gallate ${ }^{4-6}$.

Hence, the aim of these present experiments is to investigate this self-setting foaming system utilizing the day to day materials and process it to form porous ceramics. As drying and sintering are usually accompanied by shrinkage that might cause cracks and defects. Therefore, to avoid these stages in the processing of porous ceramics, these stabilized foams were added with the Portland cement in different proportions. It gave us the different characteristics porous Alumina-Portland cement porous ceramics, eliminating the tedious and energy consuming sintering step for the consolidation of the products to gain its strength.

\section{EXPERIMENTAL}

Alumina suspension was prepared by stepwise addition of alumina powder to an aqueous solution containing $0.01 \mathrm{M} / \mathrm{L}$ propyl gallate and $0.1 \mathrm{M} / \mathrm{L} \mathrm{NaOH}$. The suspension solid loading was initially fixed to 50 vol $\%$ and was homogenized with a ball mill for at least $36 \mathrm{~h}$. It was then stabilized with $2 \mathrm{wt} \%$ propyl gallate dissolved in water to $\mathrm{Al}_{2} \mathrm{O}_{3}$ and the total solid contents were changed to $15 \mathrm{vol} \%$. $\mathrm{pH}$ of the suspension was set in the basic values of more than 9 and less than 10. Above suspension was added with portland cement powder in the different amount (15 vol \% to $30 \mathrm{vol} \%$ ) and was mechanically frothed to form foams. It was kept in normal room temperature and half of it was kept in temperature controlled sterilizer with higher humidity. The setting and hydration was observed every $10 \mathrm{~h}$ until the complete setting which was observed through general penetration of the foams.

\section{RESULTS AND DISCUSSION}

The foaming of the hydrophobized suspension was performed after setting the $\mathrm{pH}$ of the suspension to the basic value of $\mathrm{pH}$ 9. The setting time of the cement without the mechanical frothing was taken in reference from the previous study ${ }^{3}$. It is

$†$ Presented to the 6th China-Korea International Conference on Multi-functional Materials and Application, 22-24 November 2012, Daejeon, Korea 
presumed that the propyl gallate molecules are partially entered onto the cement particles and inhibit the dissolution of the cement and poison the nuclei of the freshly precipitated hydrated cement phase. Therefore the setting accelerator lithium carbonate was added to the suspension mixture, acting as a nucleation agent for the hydrated cement paste ${ }^{5}$. Therefore, by processing these self-setting foams, it is observed that only a negligible shrinkage or swelling (less than 1 vol \%) during setting, which often is a problem with dried and sintered foams. This can be attributed to the fact that upon the cement hydration reaction part of the water from the suspension is incorporated into the crystalline cement structure, reducing the amount of liquid that has to be evaporated during drying ${ }^{6,7}$.

Fig. 1 shows the change in hydration reaction with the similar amount of cement but at different environmental conditions. We can see the formation of crystal like growth in described to be as new materials (e.g. gismonide) formed by the higher hydration of the cement in humid atmosphere at $35^{\circ} \mathrm{C}$. A comparative study of the samples also showed that increasing the cement concentration led to faster setting time but low hydration reaction of cement leading to lower mechanical strength.
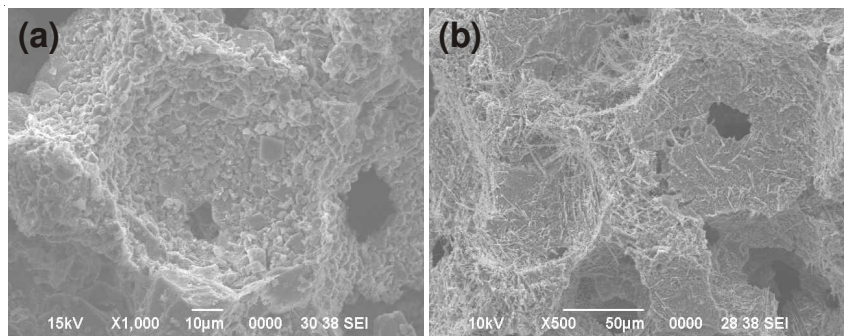

Fig. 1. Microstructures of the sample with 15 vol $\% \mathrm{Al}_{2} \mathrm{O}_{3}+25$ vol $\%$ Portland cement +10 wt $\% \mathrm{LiCO}_{3}$ (a) at room temperature and conditions and (b) at $35{ }^{\circ} \mathrm{C}$ and humid conditions

As shown in Fig. 2 we can see the change in the compressive strength and porosity of the wet foam after it has been kept under room temperature for 3 days.

There was a gradual increase in the strength of the samples with increasing volume of the cements in the hydrophobized suspension containing 15 vol $\% \mathrm{Al}_{2} \mathrm{O}_{3}$ with $\mathrm{SiO}_{2}(30 \mathrm{vol} \%)$ in

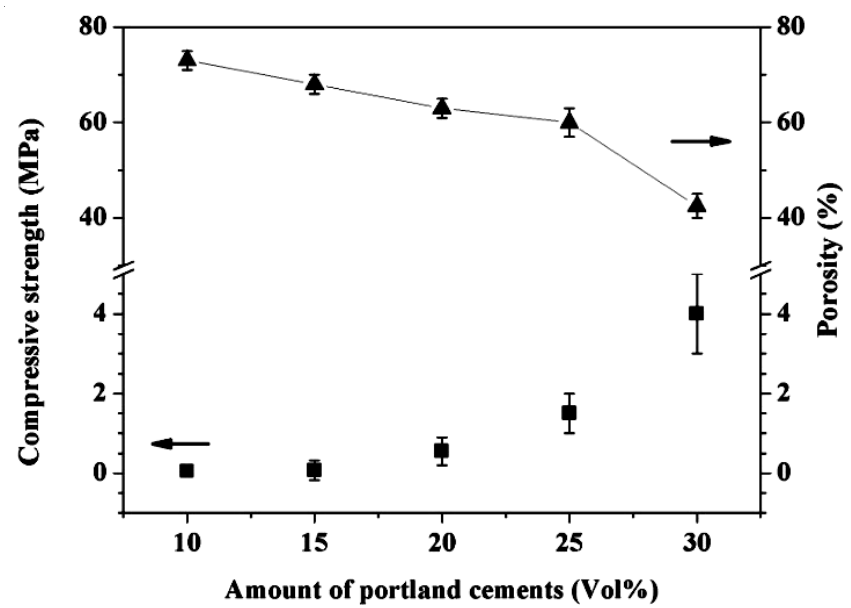

Fig. 2. Compressive strength and porosity with respect to the amount of Portland cement in the suspension after setting the ratio of 1:0.25. The gradual decrease in the porosity can be attributed to the increase in cement solids loadings which was as less as $40 \%$, with cement loading of $30 \mathrm{vol} \%$ in the suspension. Moreover, to the addition of the silica content in the constant $15 \mathrm{vol} \%$ of the alumina suspension, different vol $\%$ of cement particles were also added to calculate the change of rate of hydration and setting. Amount of accelerator used in the process were also fluctuated to get better results. The higher porosity gained were nearly $65 \%$, similar to the wet foam air content, which implies that most of the water in the wet foams is used up during the cement setting reaction and relative amount of volumetric composition of water is required for proper hydration of cement to give higher setting rate with moderate mechanical strength as to seen in Fig. 2.

\section{Conclusion}

The final microstructure featured a porosity of nearly $65 \%$ and a unique pore structure with prevailing hydration reaction of cement. As a result, self-setting ceramic composites with porosities ranging from 40 to $65 \%$ and pores with sizes between $100 \mu \mathrm{m}$ to $1 \mathrm{~mm}$ were achieved. Compared with other methods, process used to produce self-setting inorganic macro porous materials is simple and low cost and opens a door for applications where so far drying and sintering phases were the limiting factors.

\section{ACKNOWLEDGEMENTS}

This research was financially supported by the Ministry of Education, Science Technology (MEST) and The National Research Foundation of Korea (NRF) through the Human Resource Training Project for Regional Innovation and Hanseo University.

\section{REFERENCES}

1. M. Scheffler and P. Colombo, Cellular Ceramics: Structure, Manufacturing, Properties and Applications, Weinheim, Wiley-VCH, p. 645 (2005).

2. A.R. Studart, U.T. Gonzenbach, E. Tervoort and L.J. Gauckler, J. Am. Ceram. Soc., 89, 1771 (2006).

3. F.K. Juillerat, U.T. Gonzanbech, P. Elser, A.R. Studart and L.J. Gauckler, J. Am. Ceram. Soc., 94, 77 (2011).

4. R.J. Schutz and N.J. Augusta, Admixtures and Methods for Accelerating the Setting of Portland Cement Compositions, U.S. Patent No: 858,409.

5. F.K. Juillerat, U.T. Gonzanbech, A.R. Studart and L.J. Gauckler, Mater. Lett., 64, 1468 (2010).

6. F.K. Juillerat, U.T. Gonzanbech and L.J. Gauckler, Mater. Lett., 70, 152 (2012).

7. A. Pokhrel, J.G. Park, W. Zhao and I.J. Kim, J. Ceram. Process. Res., 13, 420 (2012). 